\title{
IMPACT OF SOCIO-ECONOMIC ATTRIBUTES ON THE LIVING STANDARDS OF FEMALES IN FARMING SYSTEM OF PUNJAB, PAKISTAN
}

\author{
T.I. Ullah ${ }^{1}$, H.N. Anwer ${ }^{1}$, M. Musa ${ }^{2}$ and F. Sher ${ }^{1 *}$ \\ ${ }^{1}$ Department of Sociology, Govt. College University, Faisalabad \\ ${ }^{2}$ Ayub Agricultural Research Institute, Faisalabad,
}

\begin{abstract}
In the context of farming, Punjab is bestowed with fertile land. It is a land of five rivers and friendly atmosphere for agriculture as well as for livestock. Majority of its population lives in rural areas and its major source of income is based on agriculture. Women are contributing a significant share in the field of farming. This study was carried out to investigate the effects of socio-economic factors on the living conditions of those women who are involved in any farming activities. The nature of study was quantitative. 400 women were selected through multiple sampling techniques from three different geographical zones of Punjab. The tool for data collection was interview schedule. Statistical Package of Social Science (SPSS) was used for quantitative analysis for enhancing the scope and validity of research. Bi-variate analysis was carried out for showing the relationship between variables. The study revealed positive as well as negative impacts on living conditions of women in this sector. This study shed a light on women participation as a farmer and its impact on their lives. The major suggestions were made after conducting the research that there should be proper training for women in agriculture sector. Proper health and education facilities should be provided to them and their children. Government should make policies to facilitate the women in farming system.
\end{abstract}

Keywords: Domestic chores, Education Farming activities, Female participation, Living standard.

\section{INTRODUCTION}

Pakistan as an agrarian country is dependent on agriculture. A huge chunk of population is involved in agricultural activities. Total female population of the country is $51 \%$ and almost $80 \%$ from this women population are engaged in farming system (Fayyaz, 2010).

\footnotetext{
*Corresponding author: mum96@hotmail.com
} 
Reportedly, women are contributing largely and significantly in the economy of rural areas and in agriculture sectors of almost all developing nations. They are participating in all agricultural activities with the changing socio-economic scenario in the context of agricultural development in different regions at global level. Rural women are mostly involved in managing multifarious households and practice different livelihood strategies. They mostly perform activities like growing agricultural crops, animal husbandry, preparation and collection of food, earning money as a laborer, collection of wood for fuel and bringing water for household use, involving in marketing and trading of products, look after their children and maintenance of their homes. But their contribution is not acknowledged in the context of economic contribution. They are not taken as an active employee in the definition of national account other than their contribution in organizing and looking after the family, as a whole (FAO, 2011). Women comprise a large portion of world population. Their participation in all fields is encouraging as the world scenario got a drastic change due to wave of feminism and modernism. Women are taken as a root in the development of rural area and also essential for national economic development and prosperity of the nation. They encompass $43 \%$ of the world agriculture labor force and in some countries, this proportion exceeds up to $70 \%$ (MuGeDe, 2013). According to Gerrior et al. (2008), 60\% of the respondents were physically inactive. Aggarwal et al. (2013) reported that majority of women (80\%) worked at farms in all seasons, suffered from many diseases in spring and autumn due to weather conditions. He further revealed another problem being faced by a large number of women (76\%) in agriculture sector was economic constraints which put stress on their socio-economic condition. Another precarious impact on physical condition of women farmers was shown when they applied chemicals like pesticides/insecticides on crops. Female health suffered due to the use of these hazardous chemicals while performing farming activities. Carbonates and inorganic compounds were some of the major reasons behind acute sickness like skin or eyes allergies and extreme women farmers poisoning.

Social and economic development of women is not merely the question of equalizing them with their counter parts. Rather, it is the issue of overall development of Pakistan. (Jamali, 2009). Women has a prominent role in farming, livestock and cottage industries of Pakistan. Farming women allocate more time to agricultural activities as compared to the males. Village women are involved in almost all agricultural chores like sowing, transplanting, winnowing, dying, grinding, husking, storage and post-harvest operations. Milking, making and storage of dung cakes, collection of manures, caring of diseased animals, making feed concentrates and feeding of livestock, cleaning of animal sheds, fodder chopping, and calf rearing were other relevant activities where rural women had high rate or participation (Arshad, 2009). In addition to farming work, women solely are responsible for domestic activities like cooking; taking care of children, fetching water and fuel, cleaning and maintaining the house. 
Keeping in view the above facts, this study was designed to investigate the living standards of farming women influenced by different socio-economic factors.

\section{METHODOLOGY}

Methodological techniques are considered very important for analyzing sociological problems empirically. Social research is concerned with exploring, describing and explaining social phenomena related to human behavior (Sufian, 1998). This study was conducted in Punjab province of Pakistan because this province is considered more fertile in the context of land, and many women are participating as farmers. The nature of study was quantitative because in this study deductive approach is followed for conduction of research. Survey method was used for collection of information from respondents. Multistage sampling techniques were used to select female

farmers. Sample size was 400 which were taken from three different districts of Punjab (Rawalpindi, Chiniot, Multan).The information was collected from the respondents to generalize to the whole population of under design study. The tool for data collection was interview schedule because most of the respondents were illiterate. The collected data was analyzed by using Statistical Package of Social Science (SPSS). The collected data was further analyzed by using inferential statistical techniques which were chi square and gamma test. The relationship was tested between socio-economic characteristics and living standards of respondents.

\section{RESULTS AND DISCUSSION}

The inferential analysis was carried out. The variable of living standards was constructed by food pattern, health condition, access to medical facilities, daily working hours, performing domestic chores, family and relationships, contribution in household expenditures, involvement in agricultural and livestock activities. The results are given below under tables and in description form.

\section{Hypothesis 1: Higher the age of the female in farming system, higher will be influencing on their living style.}

Table 1 represents the relationship between age of the selected females and their living style. Chi-square value $\left(\chi^{2}=26.32\right)$ showed a highly significant $(p=0.000)$ association between age of the selected females and their living style (Table 1). 
Table 1. Relationship between age of the selected females and their living style

\begin{tabular}{l|c|c|c|c}
\hline \multirow{2}{*}{ Age (in years) } & \multicolumn{3}{|c|}{ Living style } & \multirow{2}{*}{ Total } \\
\cline { 2 - 3 } & Low & Medium & High & \\
\hline Up to 20 & 15 & 26 & 6 & 47 \\
$21-30$ & 41 & 67 & 10 & 118 \\
$31-40$ & 38 & 72 & 22 & 132 \\
Above 40 & 27 & 41 & 35 & 103 \\
Total & 121 & 206 & 73 & 400 \\
& $30.3 \%$ & $51.5 \%$ & $18.3 \%$ & $100.0 \%$ \\
\hline Chi-square $=26.32($ d.f. $=6)$ & P-value $=0.000 * *$ & Gamma $=0.213$ & P-value $=0.002 * *$
\end{tabular}

Gamma statistics indicated a strong positive and significant relationship between variables (Table 1). As regards living styles, higher \% age of all age farming females had medium living style as compared to low and high living styles (Fig. 1).Women up till 40 years old (55.3\% for up to $20,56.8 \%$ for $21-30$ and $54.5 \%$ for $31-40$ years old) had statistically similar medium living style as against the lowest of $39.8 \%$ for above 40 years old (Fig. 2). Similar was the case with those of having low living style (Fig. 2). On the contrary, more women with age of above 40 years (34.0\%) were enjoying statistically high living style as compared to all other age groups (Fig. 2). It showed that selected high age farming females had high living style as compared to lower age selected women. It was further observed that majority of the lower age farming women (up till 40 years old) had low to medium level living style. On the other hand, mostly aged farming women (above 40 years old) had medium and highlevel living style. So, the hypothesis "Higher the age of the female in farming system, higher will be influence on their living standard" is accepted.

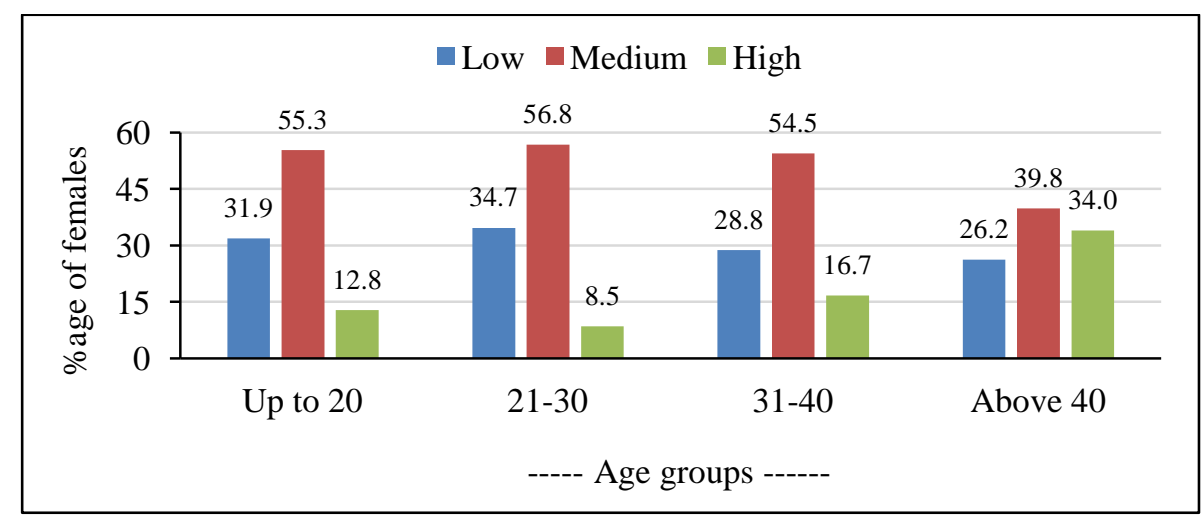

Figure 1. Comparison of living styles for different age groups 


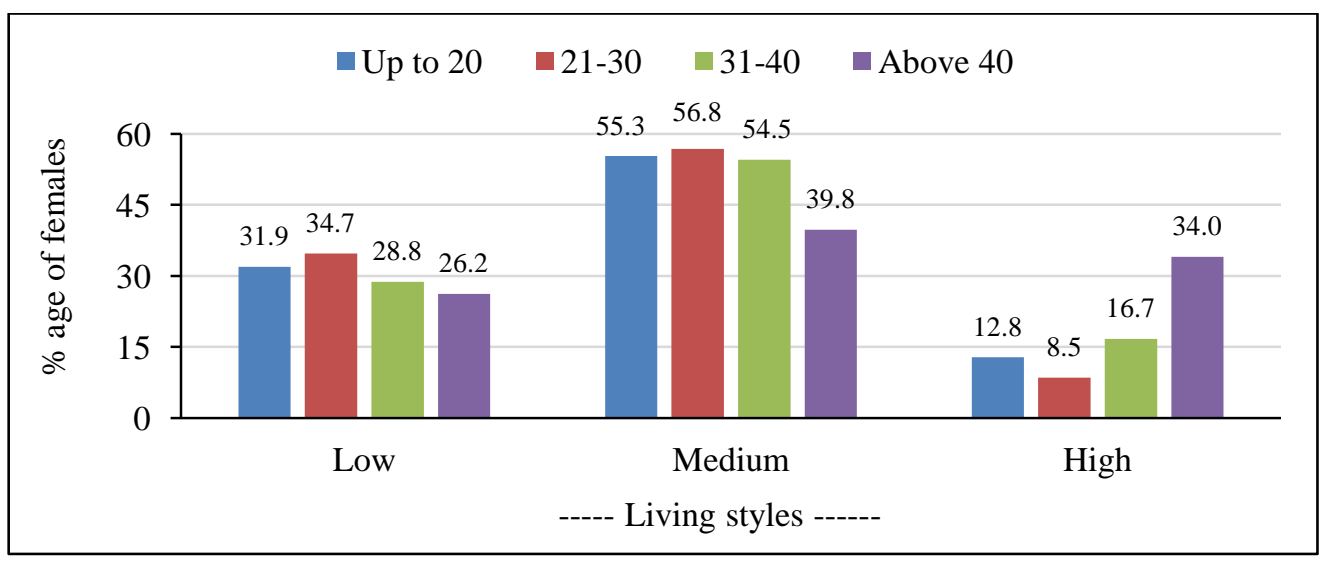

Figure 2. Comparison of age groups for low to high living styles

\section{Hypothesis 2: Higher the education of the females in farming system, higher will be influenced on their living style}

Table 2 represents the relationship between education of the selected females and their living style. Chi-square value $\left(\chi^{2}=153.97\right)$ showed a highly significant $(p$ $=0.000)$ association between education of the selected females and their living style (Table 2).

Table 2. Relationship between education of the selected females and their living style

\begin{tabular}{|c|c|c|c|c|}
\hline \multirow{2}{*}{$\begin{array}{l}\text { Education of the } \\
\text { selected women }\end{array}$} & \multicolumn{3}{|c|}{ Living style } & \multirow[t]{2}{*}{ Total } \\
\hline & Low & Medium & High & \\
\hline Illiterate & 93 & 171 & 6 & 270 \\
\hline Literate & 6 & 13 & 11 & 30 \\
\hline Primary Pass & 10 & 12 & 30 & 52 \\
\hline Middle pass & 7 & 5 & 10 & 22 \\
\hline Matric and above & 5 & 5 & 16 & 26 \\
\hline \multirow[t]{2}{*}{ Total } & 121 & 206 & 73 & 400 \\
\hline & $30.3 \%$ & $51.5 \%$ & $18.3 \%$ & $100.0 \%$ \\
\hline
\end{tabular}

Gamma statistics indicated a strong positive and significant relationship between variables (Table 1). As regards living styles, qualified women from primary to above matric (57.7\% Primary, $45.5 \%$ middle and $61.5 \%$ matric and above) were enjoying high standards of living as compared to illiterate (2.2\%) and literate (36.7\%) females (Fig. 3). Majority of illiterate and literate females had low to medium living styles. 
As regards living style, most of illiterate and literate women had low (34.4\%) or medium (63.3\%) living standards as compared to other educational groups (Fig. 4). On the contrary, most of the farming female community enjoying high standard of living were educated (Fig. 4), showing thereby that educated farming females had good living style as compared to illiterate women. So, the hypothesis "Higher the education of the females in farming system will be influencing on their living style" is accepted.

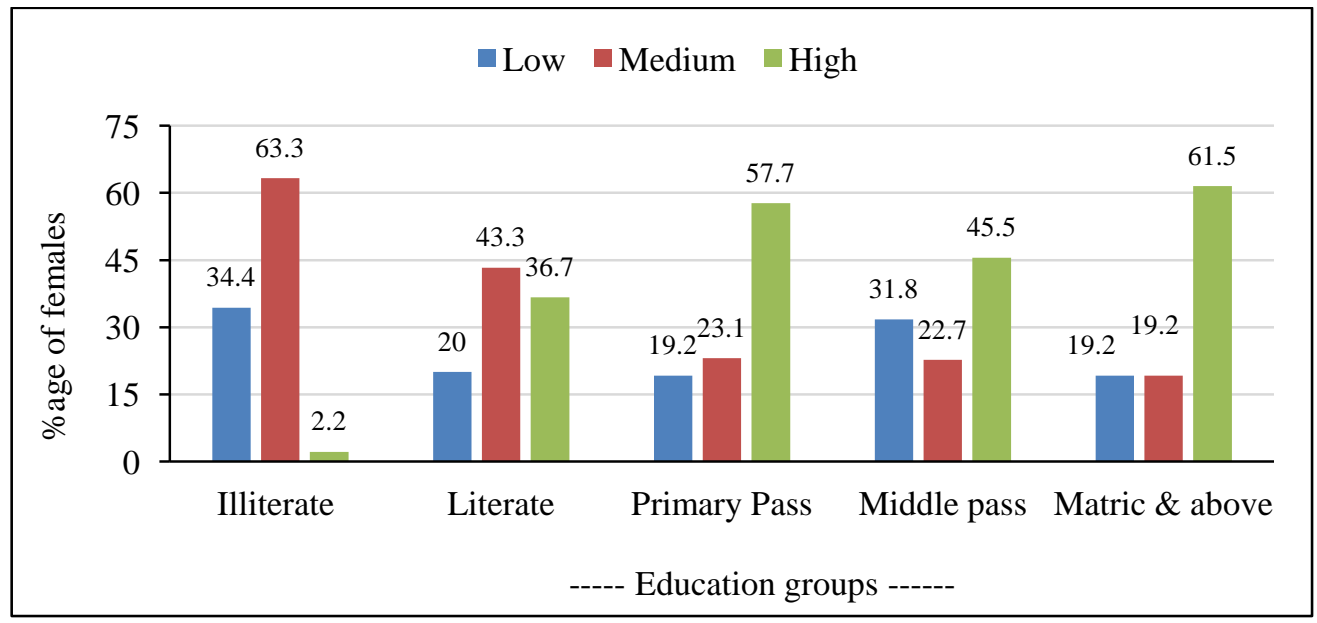

Figure 3. Comparison of living styles for different educational groups

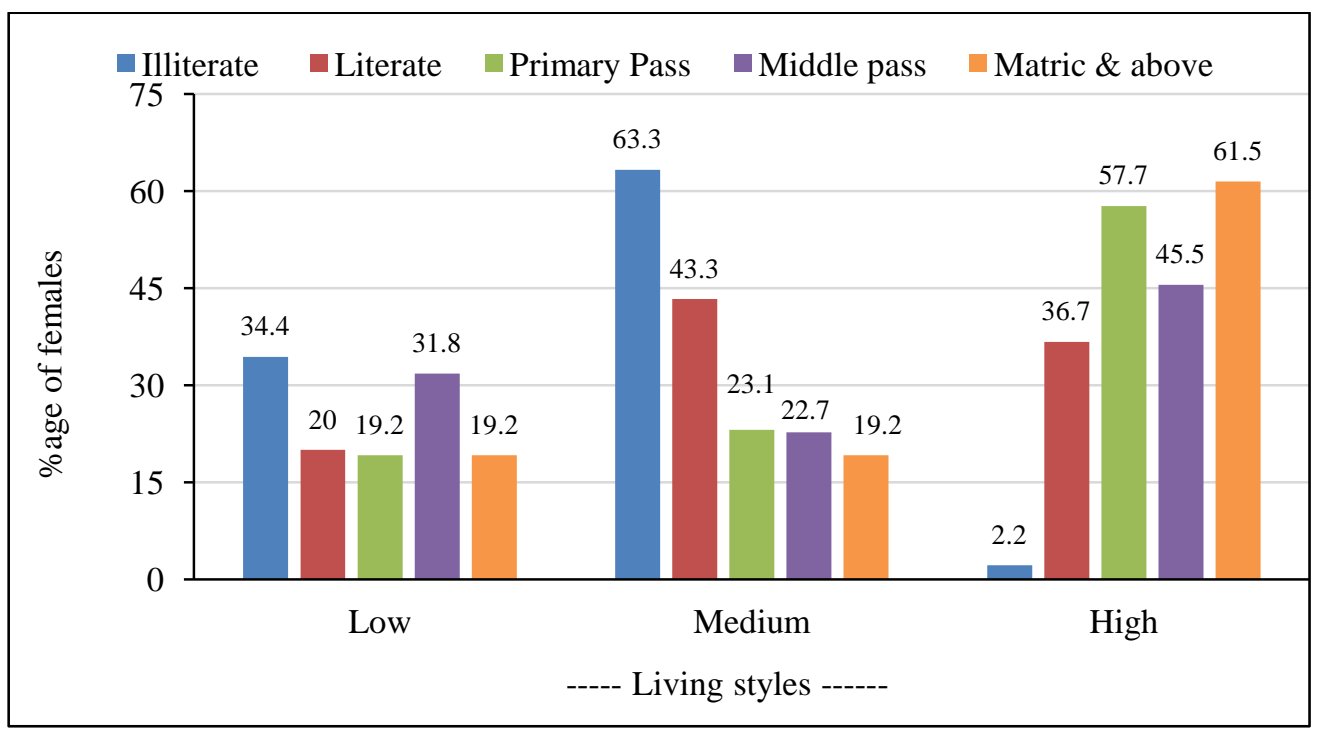

Figure 4. Comparison of educational groups for low to high living styles 


\section{Hypothesis 3: Higher the income of household of females in farming system, higherwill be influenced on their living style}

Table 3 represents the relationship between total household income of the selected females and their living style. Chi-square value $\left(\chi^{2}=54.11\right)$ showed a highly significant $(p=0.000)$ association between household income of the selected females and their living style (Table 3).

Table 3. Relationship between household income of the selected females and their living style

\begin{tabular}{l|c|c|c|c}
\hline \multirow{2}{*}{$\begin{array}{c}\text { Household income } \\
\text { (Rs.) }\end{array}$} & \multicolumn{3}{|c|}{ Living style } & \multirow{2}{*}{ Total } \\
\cline { 2 - 4 } & Low & Medium & High & \\
\hline $80000-100000$ & 53 & 106 & 16 & 175 \\
$100001-120000$ & 45 & 39 & 22 & 106 \\
$120001-140000$ & 10 & 32 & 7 & 49 \\
$140001-160000$ & 8 & 14 & 10 & 32 \\
$160001-$-above & 5 & 15 & 18 & 38 \\
Total & 121 & 206 & 73 & 400 \\
& $30.3 \%$ & $51.5 \%$ & $18.3 \%$ & $100.0 \%$ \\
\hline
\end{tabular}

Chi-square $=54.11($ d.f. $=8) \quad$ P-value $=0.000 * * \quad$ Gamma $=0.251 \quad$ P-value $=0.000 * *$

$* *=$ Highly significant

Gamma statistics indicated a strong positive and significant relationship between variables (Table 3). As regards living styles, majority of the lower income up till Rs. $1,40,000$ farming women had low to medium living style (30.3-60.6\% women having income of Rs 80,000-100000, 36.8-42.5\% women having income of Rs. 100001120000 , 20.4-65.3\% women having income of Rs 120001-140000, respectively). On the other hand, majority of the women having high income (Rs. 140001 and above) had medium to high level living style (Fig. 5). 31.3\% women having income of Rs. 140001-160000 and 47.4\% having income above Rs. 160001 were enjoying high standard of living as compared to a smaller number of female farming community (Fig. 6), showing thereby that farming females having high income were enjoying high standard of living as compared to those having low income. So, the hypothesis "Income of household of females in farming system will be influencing on their living style" is accepted. 


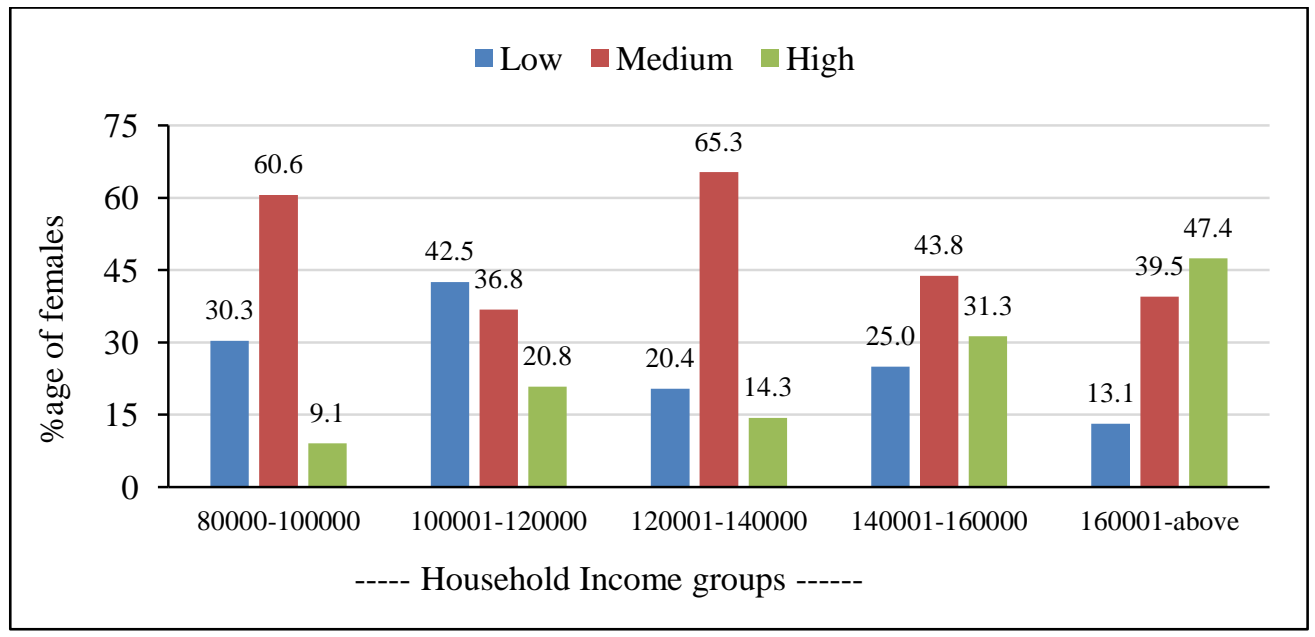

Figure 5. Comparison of living styles for different household income groups

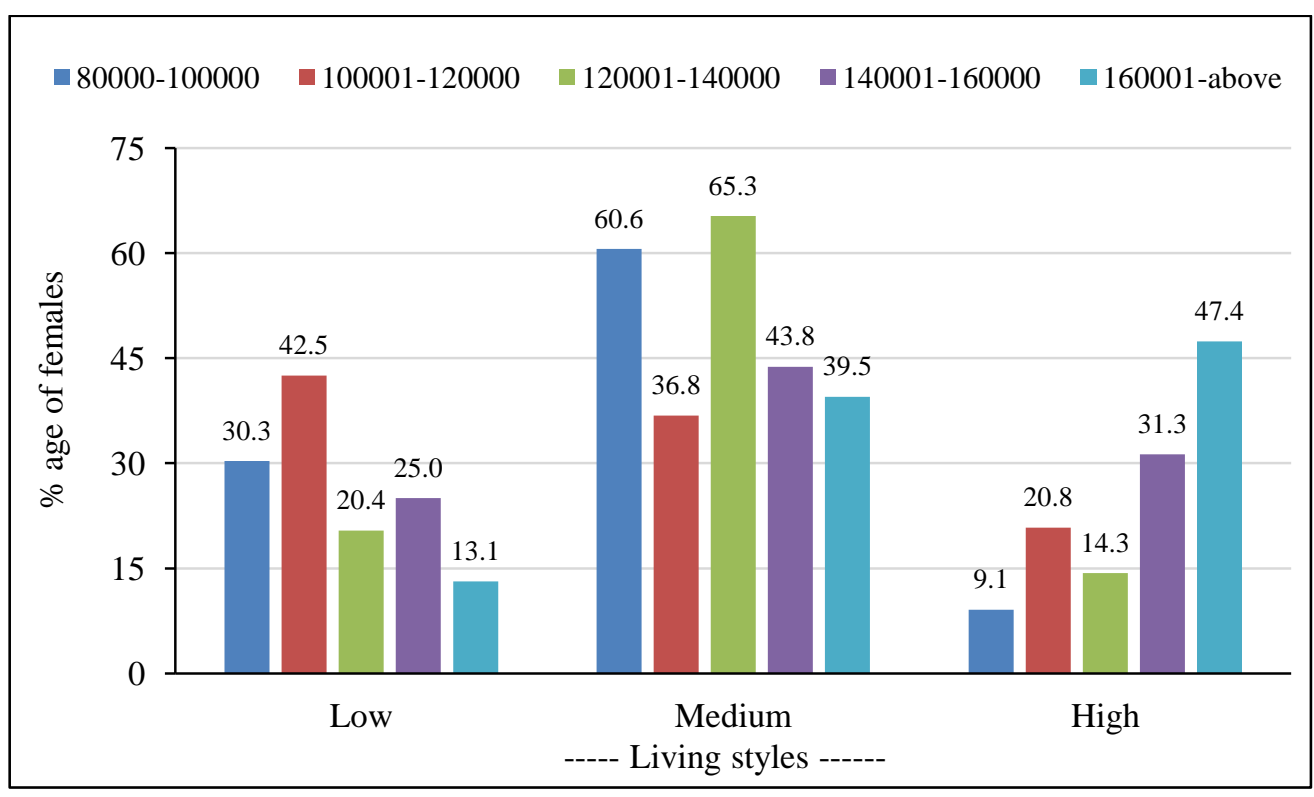

Figure 6. Comparison of household income groups for low to high living styles

\section{Hypothesis 4: Family structure of females in farming system will be influenced on their living style}

Table 4 represents the relationship between family type of the selected females and their living style. Chi-square value $\left(\chi^{2}=25.06\right)$ shows a highly significant $(p=0.000)$ association between family type of the selected females and their living style (Table 4). 
Table 4. Relationship between family type of the selected females and their living style

\begin{tabular}{l|c|c|c|c}
\hline \multirow{2}{*}{ Family type } & \multicolumn{3}{|c|}{ Living style } & Total \\
\cline { 2 - 4 } & Low & Medium & High & \\
\hline Nuclear & 42 & 50 & 4 & 96 \\
Joint & 37 & 78 & 42 & 157 \\
Extended & 42 & 78 & 27 & 147 \\
Total & 121 & 206 & 73 & 400 \\
& $30.3 \%$ & $51.5 \%$ & $18.3 \%$ & $100.0 \%$ \\
\hline
\end{tabular}

Chi-square $=25.06($ d.f. $=4) \quad$ P-value $=0.000 * * \quad$ Gamma $=0.177 \quad$ P-value $=0.019 *$

$* *=$ Highly significant $\quad *=$ Significant

Gamma statistics indicated a positive and significant relationship between variables Table 4). It means that joint and extended families' farming females had good living style as compared to nuclear families' females. As regards living styles, majority of the farming women of all three family systems (Fig. 7) had medium living style (52.1\% of nuclear, $49.7 \%$ of joint and $53.1 \%$ of extended families). Whereas, higher percentage of females of nuclear families (43.8\%) had low living standard than those of joint (23.6\%) and extended (28.6\%) families (Fig. 8). In terms of medium living style, all the three families had almost similar percentage of females, while a greater number of females of joint families (26.8\%) were enjoying high living styles (Fig. 8), followed by females of extended families (18.4\%). So, the hypothesis "Family structure of females in farming system will be influencing on their living style" is accepted.

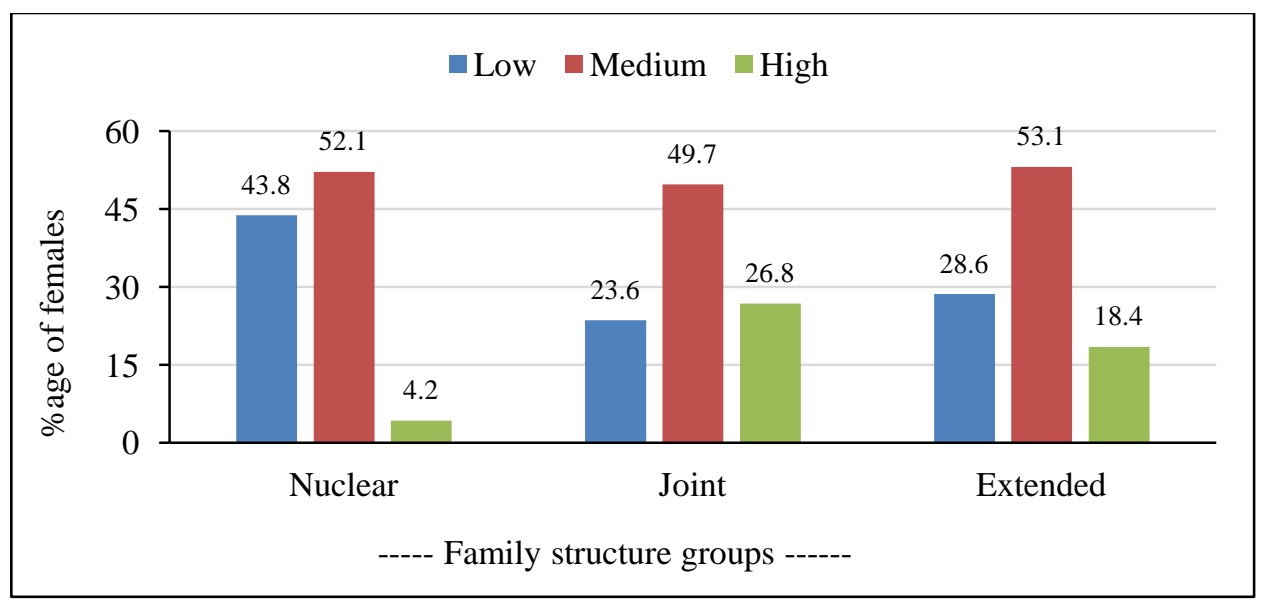

Figure 7. Comparison of living styles for different family structure groups 


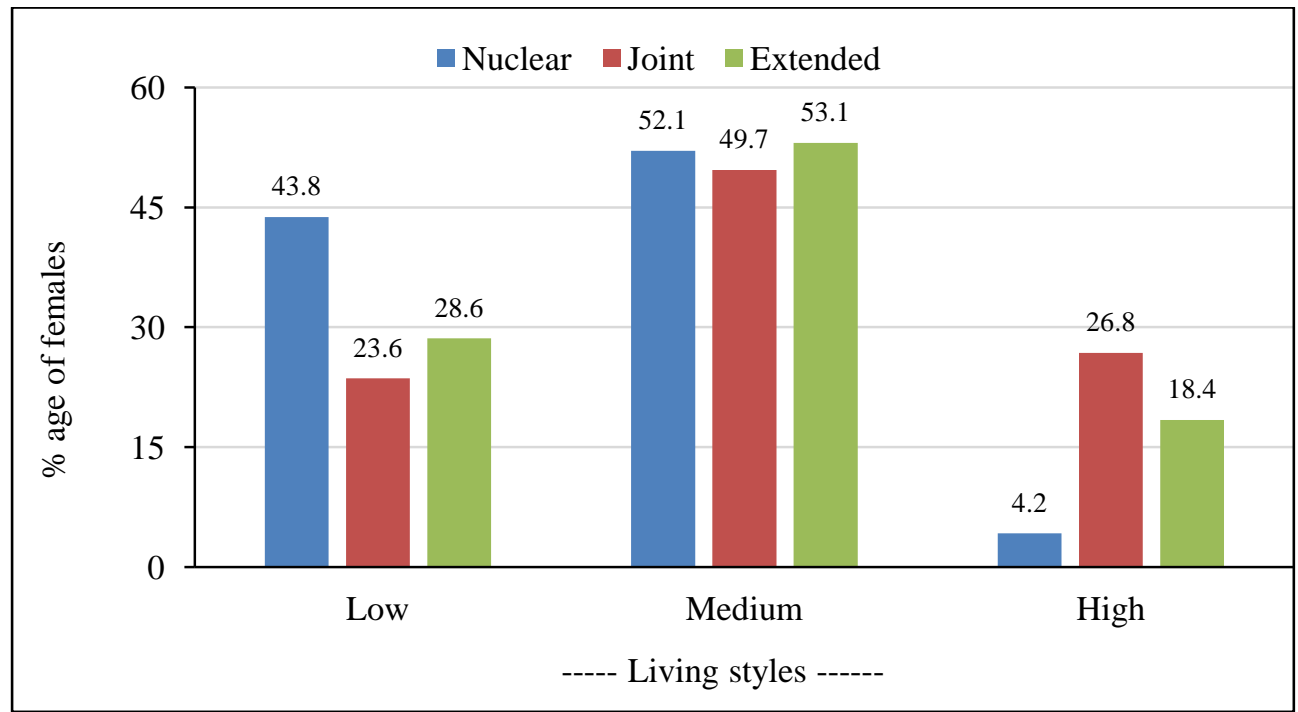

Figure 8. Comparison of family structure groups for low to high living styles

Hogg and Carrington (2006) found that the patriarchy was very strong in rural areas of Australia as compared to the urban ones. This traditional system was deeply knitted in rural ways of life. It strongly existed in interaction patterns and it was the base of power distribution in rural areas. A study conducted by Madani (2007) on women employment revealed that there were some major factors which pushed women toward getting employment in any sector. The major motivational force which researcher suggested was well-being of their children and improving standard of their life. In our study, the socio-economic attributes like age, family structure, education and income were influencing the life style of women in farming system. All indicators were directly affecting their life style. Dhillon (2007) observed that the women working at farms were of age ranging from 24 to 56. Most of them were from age group of 35 to 45 . Majority of the respondents were not educated at all. Our results are in conformity with those of Dhillon (2007). In this study, 250 out of 400 females involved in farming were of age ranging 21-40 years old (Table 1), while 270 were illiterate (Table 2). Similarly, the study conducted by Hashmi (2008) in the rural areas of Punjab revealed that women were the major contributors to livestock activities in Punjab. Males generally were involved in milking and fodder chopping. All other work was done by female. Total time donated by males was 2.83 hours per day while women donated 4.71 hours a day in livestock activities. The increased participation of women in livestock activities resulted in reduction of poverty. This study also confirmed above results that $31.3 \%$ women having income of Rs. 140,001160,000 and $47.4 \%$ having income above Rs. 160,001 were enjoying high standard of living (Fig. 6), showing thereby that farming females having high income were enjoying high standard of living as compared to those having low income. Nisha 
(2008) revealed that labourer did not enjoy maximum days of employment during whole year. They got maximum work during weeding, harvesting and postharvest operations. Female labourer had to suffer from unemployment when there was offseason of farming in summer. They had to search for work on summer season. It was also found that during the times of unemployment, women agricultural workers resulted in negative impact on income of labourer, family expenditures \& their savings and debt condition, which was the main cause of degradation of their living standard. Sometimes, labourer had to migrate and adopt other occupations. It was not compulsory that high rate workforce engagement would always result in increased welfare levels. However, higher educational capacities, assets and income would bring increased welfare level (Fig. 3-6).

Chiong-Javier (2009) narrated that women were accomplishing central role to meet the growing food demand for their household as well for their community in almost all developing countries, but they had to face health issues including malnutrition that were the results of poor economic condition and extra work burden. This may be due to no or less education (Fig. 3-4). Our findings are also supported by those of Bharathi and Chhaya (2009) who also found the lack of formal education as the main problem faced by farmwomen. Lal and Khurana (2011) also acknowledged that a large number of females in developing regions were associated with agriculture. $\mathrm{He}$ further stated that more than 50\% women in Asia were getting their employment in this sector. This population was considered most active population in term of economic benefits but illiteracy and lack of skills among females were considered the major reasons to keep women in subsistence agriculture. This study also proved that educated farming females had good living style as compared to illiterate women (Fig. $3-4)$. On the average, $54.9 \%$ educated farming women (61.5\% women of Matric and above, $45.5 \%$ Middle pass and $57.7 \%$ Primary pass) were enjoying high standard of living against $2.2 \%$ illiterate farming women (Fig. 4).

On the contrary, findings of Kalyani et al. (2011) showed that contribution of tribal women to household income was much more than that of the men although these women belonged to poor families and faced cultural constraints. Their overall participation was very high despite of their restricted access to resources required for effective agricultural production. They also spent longer hours in farming work as compared to men. Goswami (2013) gave his remarks after doing research in Assam that women with poor economic were playing productive role in household income by working as a labour despite their economically marginalized condition. They were supporting their families even with their meagre income and ameliorating economic condition of their family members. Women accepted to work in farms because they could not get employment without proper training or education and but that employment opportunities were not permanent. It was also proved that despite having more shares of females as agricultural labour than men, they get lower wages than males. Quisumbing and Pandolfelli (2009) narrated that women might have the modes of transformation which were culturally unsuitable for them. They faced 
harassment by the market and health officials when they sold their agricultural yield outside the market boundaries due to high cost of permits. The shortage of time forced women to sell their produce on low rates.

\section{CONCLUSION}

It may be concluded that female participation in farming system had positive impacts on their life style. They are still considered invisible workers in farming system due to lack of right to take decision in any matters. They had less access to market and their opinion was not considered while taking any decision regarding farming activities. It was considered a male profession, so their efforts were acknowledged and appreciated as whole. After bivariate analysis, the socio-economic attributes like age, family structure, education and income were influencing the life style of women in farming system. All indicators were directly affecting their life style. It also revealed after conducting analysis that age, education and time spending on farms were influencing female participation in farming system. Study concluded that women had low level of income, their living style was also low as compared to women with high level of income,but the positive aspect was that they had very significant contribution in household expenditure and had to some extent economic independence.

\section{REFERENCES}

Aggarwal, H., Sharma, S. and Sharma, R. (2013). A study of agricultural activities performed by rural women and problems faced by them in Jammu District of Jand K States. International Journal of Science and Research Publication, 3(1): 1-3.

Arshad, S., Muhammad, S., Randhawa, M.A., Ashraf, I. and Mehmood, K. (2010). Rural women's involvement in decision-making regarding livestock management. Pakistan Journal of Agricultural Science, 47(2): 1-4.

Bharathi, R.A. and Badiger, C. (2009). Constraints and suggestions of self-help groups under the project empowerment of women in agriculture. Karnataka Journal of Agricultural Sciences, 22 (2): 457-459.

Chiong-Javier, M.E. (2009). Health Consequences of Rural Women's Productive Role in Agriculture in the Philippines and Other Developing Countries. Journal of International Women's Studies, 10(4): 95-110.

Dhillon, M.K. (2007). Involvement of farm women in agricultural and allied activities-factors associated and constraints faced. Indian Journal of Social Research, 48(3): 221-227.

FAO. (2011).Therole of women in agriculture.ESA Working Paper No. 11-02. (http://www.fao.org/3/am307e/am307e00.pdf)

Fayyaz, S. (2010). Making Sense of Pakistan (review). The Middle East Journal, 64(1):146.

Gerrior S.A, Crocoll, C., Hayhoe, C.R. and Wysocki, J. (2008). Challenge and opportunities impacting the mental health of rural women. Journal of Rural and Community Psychology, E11(1): 1-19. 
Goswami, C. (2013). Female agricultural workers in Assam: A case study of Darrang District. International Journal of Science and Research Publications, 3(2): 1-5.

Hashmi, A.H. (2008). Socio-economic impact of livestock towards poverty alleviation in rural areas of Central Punjab, Pakistan. Ph.D. Rural Sociology Dissertation. University of Agriculture, Faisalabad, Pakistan.

Hogg, R. and Carrington, K. (2007). Policing the rural crisis. Sydney, NSW: Criminology and the study of rural crime: its approach \& methodology. Federation Press, Australia.

Jamali, K. (2009). The role of rural women in agriculture and its allied fields: A case study of Pakistan. European Journal of Social Science, 7(3): 74-75.

Kalyani, K.S., Krishnamurthy, V., Rao, C.C. and Kumari, N.A. (2011). Role Performance of Tribal Women in Agriculture - A study in Agency Area of East Godavari district, Andhra Pradesh". Journal of Dairying, Foods and Home Science, 30(3): 221-224.

Lal, R. and Khurana, A. (2011). Gender issues: the role of women in agricultural sector. Zenith International Journal of Business Economics \& Management Research, 1(1): 29-39

Madani, G.F. (2007). Studying on the affecting factors on women's employment. M.Sc. (Hons.) Agri. Diss. Humanities Science \& Research Branch, Islamic Azad University, Iran.

MuGeDe, S.M. (2013). The Role of Rural Women in Agriculture. Women, Gender and Development, Republic of Mozambique - Southern Africa. (www.wfo-oma/women-inagriculture/articles/the-role-of-women-in-agriculture-html)

Nisha, N. (2008). Woman Labour in Agriculture- An economic analysis. M.Sc. (Hons.) Agri. Diss. Agricultural Economics, Department of Agricultural Economics, University of Agricultural Science, Dharwad, India.

Quisumbing, A.R. and Pandolfelli, L. (2009). Promising approaches to address the needs of poor female farmers: resources, constraints, and interventions. World Development, 38(4): 581-592.

Sufian, A.J.M. (1998). Methods and Techniques of Social Research. The University Press Ltd; revised edition (Edi. 1998). 